Anuario de

Derechos Humanos 2005 


\section{La Nueva Institucionalidad de la Protección de los Derechos de los Consumidores en nuestro País a partir de la Ley $N^{\circ} 19.955$}

Francisco Fernández Fredes*
E I día 14 de julio del año 2004 se publicó en el Diario Oficial la Ley No 19.955 que vino a modificar la ley marco de Protección de los Derechos de los Consumidores, $N^{\circ} 19.496$, vigente desde el 5 de junio del año 1997 (en adelante "LPC").

La nueva normativa es un importante eslabón que se incorpora al creciente sistema de protección de los derechos de los consumidores en nuestro país ${ }^{1}$. Cuando califico de importante la modificación legal lo hago con justa causa, pues al margen de que podamos discrepar sobre aspectos particulares de su contenido -deficiente redacción de algunas de sus disposiciones, mal entendimiento y sesgo en la omisión o en el tratamiento de algunas instituciones propias del nuevo Derecho del Consumidor, entre otras-, no podemos estar más de acuerdo que, en el plano macro o general, constituye un notable avance.

Para justificar lo afirmado en el acápite anterior, a grosso modo revisaré los principales y positivos avances en el ámbito sustantivo, procesal y orgánico en materia de consumo, contenidos en la modificación en comento:

\section{Sustantivamente}

Es imperioso explicar para lo que se mencionará más adelante que la LPC desde su texto original del año 1997 reconoce o prescribe tres reglas fundamentales que deben ser tenidas en cuenta para su aplicación, a saber:

a) En cuanto a los sujetos intervinientes en el acto de consumo, éstos deben ser, por una parte, un consumidor final y, por la otra, un proveedor, en los términos especialmente definidos en la ley².

b) En cuanto a la naturaleza jurídica del acto de consumo, éste debe ser un acto civil para el consumidor y de comercio para el proveedor, esto es, el acto de consumo es un acto mixto, en palabras de la doctrina del Derecho Comercial.

c) Legalidad. Los actos de consumo que se encuentren regulados por leyes especiales se regirán por ellas y, supletoriamente, en lo que éstas no prevean, se les aplicarán las normas de la LPC.
* Abogado, Presidente de la Comisión Asesora Presidencial para la Protección de los Derechos de las Personas.

1 Integrado,

fundamentalmente, por la Ley $N^{\circ} 19.496$, sobre Protección de los Derechos de los Consumidores; Ley 19.659, sobre Modificación de las Normas de Cobranza Extrajudicial; Ley $\mathrm{N}^{\mathrm{o}}$ 19.628, sobre Protección a la Vida Privada de las Personas; DL № 211, de 1973, que Protege la Libre Competencia; Ley No 18.168, General de Telecomunicaciones, entre otras.

2 Ley $N^{\circ} 19.496$, artículo $1^{\circ}$ $N^{\circ} 1$ : "Consumidores o usuarios: las personas naturales o jurídicas que, en virtud de cualquier acto jurídico oneroso, adquieren, utilizan o disfrutan, como destinatarios finales, bienes o servicios"; $\mathrm{N}^{\circ} 2$ : "Proveedores: las personas naturales o jurídicas, de carácter público o privado, que habitualmente desarrollen actividades de producción, fabricación, importación,

Este comentario, junto con el documento principal a que se refiere, están disponibles en formato digital en www.anuariocdh.uchile.cl 
construcción, distribución o comercialización de bienes o prestación de servicios a consumidores, por las que se cobre un precio o tarifa".

3 Letras d), e) y f) del artículo $2^{\circ}$ de la Ley $\mathrm{N}^{\circ}$ 19.496, modificado por la Ley $\mathrm{N}^{\circ} 19.955$.

4 Artículo $2^{\circ}$ bis de la Ley $N^{\circ} 19.496$, añadido por la Ley $\mathrm{N}^{\circ} 19.955$.

5 Artículo $3^{\circ}$ bis de la Ley $\mathrm{N}^{\circ} 19.496$, agregado por la Ley $\mathrm{N}^{\circ} 19.955$.
Entrando en la materia de fondo, podemos señalar que uno de los principales avances introducidos por la modificación legal está dado por la ampliación del ámbito de aplicación de la LPC a materias que estaban excluidas de su regulación o, a lo menos, su inclusión resultaba discutible a la luz de las reglas de aplicación antes descritas. Tal era el caso, por ejemplo, de la compra que realizaba un consumidor de una vivienda nueva a una empresa inmobiliaria.

Lo anterior fue superado, a lo menos formalmente, por la modificación legal en comento que, expresamente, sujeta a las disposiciones de la ley nuevos actos de consumo que sin duda resultan esenciales para todo consumidor en ámbitos tales como los de vivienda, salud y educación ${ }^{3}$.

Además, se deja meridianamente claro (lo que, para algunos intérpretes, no lo estaba en la ley original) que, como ya se mencionó, en los casos en que el acto de consumo se encuentra regulado en normas jurídicas especiales, como es el caso de los servicios básicos domiciliarios, entre otros, la LPC se aplica en forma supletoria. Tal circunstancia ha sido esclarecida por el legislador en la reciente modificación, disponiendo además que aunque exista norma especial es aplicable la LPC en lo relativo al procedimiento en las causas en que esté comprometido el interés colectivo o difuso de los consumidores o usuarios y al derecho a solicitar indemnización mediante dicho procedimiento ${ }^{4}$.

Por otra parte, en cualquier legislación de protección al consumidor de inspiración moderna la columna vertebral de todo su plexo normativo la constituye el reconocimiento de ciertos derechos básicos a los consumidores -sujetos que protege-, lo que nuestra ley realiza mediante una enumeración de ellos en su artículo $3^{\circ}$, sin perjuicio de los contenidos en otras disposiciones de la misma, como, por ejemplo, el derecho a garantía (consagrado en los artículos 19 y siguientes).

No obstante, la LPC no reconocía hasta ahora el derecho a retracto, que consiste en la facultad del consumidor para poner término a la relación de consumo que lo une con el proveedor, por su sola voluntad, en los casos, plazos y condiciones establecidos por la ley.

Esta modificación asegura tal derecho en forma limitada, al establecer su aplicación sólo en aquellas relaciones de consumo que han derivado o pueden derivar de una "decisión poco reflexiva" del consumidor: los actos celebrados en reuniones convocadas o concertadas por el proveedor a fin de ofrecer sus productos o servicios a los consumidores, o aquellos propuestos por medios electrónicos o cualquier otro que opere a distancia; así como en los contratos educacionales celebrados por alumnos de primer año de la enseñanza superior ${ }^{5}$.

En este mismo contexto de los derechos básicos de los consumidores se incorpora expresamente que "el silencio no constituye aceptación en materia de consumo". Con ello, nuestra legislación se hace eco de los estándares normativos del Derecho del Consumidor comparado, especialmente de lo preconizado por la Ley Modelo para América Latina y el Caribe de Consumers International. 
Finalmente, en el ámbito de los derechos básicos es destacable la contribución del Derecho del Consumidor a la contingente discusión sobre la indemnización del daño moral en materia contractual. La modificación a la LPC reconoce su procedencia positivamente al indicar que es un derecho básico del consumidor "la reparación adecuada y oportuna de todos los daños materiales y morales en caso de incumplimiento de cualquiera de las obligaciones contraídas por el proveedor...".

Otro avance sustantivo destacable es la incorporación a la regulación de los contratos por adhesión ${ }^{6}$ de una causal o hipótesis genérica de abusividad. Dicho sea de paso, la LPC nos aporta la única definición y regulación positiva que conoce nuestro ordenamiento jurídico de esta especie de contratos.

En los contratos por adhesión en materia de consumo existe una parte más fuerte que obviamente es el predisponente o proveedor y, por tal motivo, la LPC, asumiendo la teoría favor debilis, realizaba hasta ahora una enumeración taxativa de estipulaciones o condiciones que se consideran abusivas ${ }^{7}$. Entre ellas se prohíbe reservarse la facultad de modificar unilateralmente el contrato, suspenderlo o dejarlo sin efecto, invertir la carga de la prueba en perjuicio del consumidor y otras estipulaciones igualmente abusivas. No obstante, las hipótesis de abusividad contenidas en la ley constituían una "lista cerrada o negra", en terminología de la doctrina europea en materia de consumo.

Con la modificación legal, se incorpora una nueva hipótesis que es genérica o abierta $^{8}$, siguiendo los términos en que lo hacen los derechos más modernos en esta materia, como es el caso de la LPC de Argentina (Ley $N^{\circ} 24.240$, artículo 37).

\section{Procedimiento}

En este aspecto es donde se destaca un mayor progreso en la modificación para el Derecho del Consumidor de nuestro país, toda vez que se reconoce un procedimiento para el ejercicio de las acciones supraindividuales de los consumidores (colectivas y difusas).

Conviene destacar que la LPC desde su versión original del año 1997 reconoce derechos indivisibles o comunes para una pluralidad de consumidores determinados, determinables o indeterminados ${ }^{9}$, como, por ejemplo, en los casos de publicidad engañosa, cláusulas abusivas incorporadas en un contrato por adhesión o en la introducción de un producto peligroso en el mercado, pero, paradójicamente, el ejercicio de la acción respectiva se debía realizar mediante un procedimiento judicial individual, amparado en los principios clásicos de la legitimación subjetiva y del efecto relativo de la sentencia. Todo ello en contraposición a la naturaleza de los actos de consumo que conllevan una nota de masividad y a los principios modernos del Derecho del Consumidor, especialmente en materia de efecto erga omnes o ultrapartes de la sentencia.
6 Artículo $1^{\circ} \mathrm{N}^{\circ} 6$ : "Contrato de adhesión: aquel cuyas cláusulas han sido propuestas unilateralmente por el proveedor sin que el consumidor, para celebrarlo, pueda alterar su contenido".

7 Artículo 16 de la Ley $\mathrm{N}^{\circ}$ 19.496

8 Artículo 16: No producirán efecto alguno en los contratos de adhesión las cláusulas que (...) letra g) "En contra de las exigencias de la buena fe, atendiendo para estos efectos a parámetros objetivos, causen en perjuicio del consumidor un desequilibrio importante en los derechos y obligaciones que para esta parte se deriven del contrato. Para ello se atenderá a la finalidad del contrato y a las disposiciones generales o especiales que lo rigen...".

9 Entre otros, en los artículos 28, 31, 45, 54 (actualmente 58, inciso $\left.3^{\circ}\right)$ de la Ley $N^{\circ} 19.496$. 
10 Artículo 51 de la Ley $N^{\circ}$ 19.496, modificado por la Ley $\mathrm{N}^{\circ} 19.955$.

11 Artículo $6^{\circ}$ y 11 bis de la LPC.
La modificación legal reconoce un procedimiento para el ejercicio, conocimiento y resolución de las demandas en que se comprometan acciones colectivas y difusas. El proyecto de modificación siguió de cerca en esta materia el sistema de class action norteamericano.

Esta nueva institucionalidad permite variadas ventajas; entre las más destacables, figura la materialización de uno de los derechos básicos de toda persona -en este caso, el consumidor- por el hecho de ser tal: el acceso a la justicia. Mientras subsistía el sistema con solo procedimiento individual, se hacía para un consumidor poco atractivo accionar ante los tribunales de justicia. Piénsese, por ejemplo, en una empresa de servicios básicos que cobrara $\$ 100$ de más en la facturación a cada uno de sus usuarios (supongamos que son cuatro millones). Individualmente no resultaba practicable este accionar.

Además que proceder individualmente hace desgastar innecesariamente los recursos de nuestros tribunales de justicia, al tramitar numerosas causas por los mismos hechos, colocaba en riesgo el decoro de la judicatura al exponer a los consumidores a fallos asimétricos en situaciones análogas.

Por otra parte, no podemos soslayar que al reconocerse en este nuevo procedimiento la posibilidad de que representen estos derechos comunes -colectivos o difusos- ante los tribunales de justicia sujetos del sector privado -asociaciones de consumidores o un grupo de 50 o más consumidores ${ }^{10}-$, se democratiza el derecho, al permitir que se fiscalice la legalidad de los actos en materia de consumo no sólo por parte de los órganos del Estado sino también de la sociedad civil.

En este aspecto procesal igualmente se genera un cambio destacado al crearse un procedimiento de mínima cuantía que tiene como característica esencial no requerir de patrocinio de abogado (lo que ya estaba en la LPC) y, además, el ser de única instancia, lo que implica que la tramitación judicial de los pequeños conflictos en materia de consumo sea más breve.

\section{Orgánica}

Se mejora la institucionalidad de las asociaciones de consumidores al establecer un procedimiento más expedito para la constitución de estos importantes actores sociales en materia de consumo y, además, al contemplar una modalidad de apoyo financiero para ellas a través de la creación de un fondo concursable para la realización de algunos de los proyectos que lleven a cabo ${ }^{11}$.

Dentro de este aspecto, destaca el reconocimiento de la "participación consultiva" de las asociaciones de consumidores en una materia de esencial importancia para los consumidores, como lo es la fijación de las tarifas de los servicios básicos domiciliarios: electricidad, telefonía, agua potable, alcantarillado. Así se potencia la expresión de los consumidores y usuarios en los asuntos de interés general que les conciernen. 


\section{Deficiencias}

Sin perjuicio de que los avances descritos constituyen en general una notoria mejoría de nuestro marco legal en esta materia, la nueva ley no está exenta de deficiencias y omisiones importantes, entre las que cabría mencionar:

- El derecho a retracto incorporado para los casos de venta por medios electrónicos u otros que operan a distancia puede resultar letra muerta o ineficaz, ya que el legislador reconoce este derecho "a menos que el proveedor haya dispuesto expresamente lo contrario...". Por otra parte, el derecho a retracto sobre contratos de prestación de servicios educacionales resulta extremadamente limitado, al considerar solamente a alumnos de primer ingreso en establecimientos de educación superior privados y, lo que es más grave, no reconoce las circunstancias de fuerza mayor que impiden eventualmente al educando continuar con sus estudios, ya que igualmente en dichos casos deberá cumplir los pagos aunque no acceda al servicio.

- En los contratos por adhesión, faltó incorporar una disposición legal que permitiera al juez de la causa ejercer una función integradora del contrato para garantizar la conmutatividad y subsistencia del mismo en los casos de nulidad parcial por abusividad de algunas de sus estipulaciones.

- Muy escuálida es la reglamentación en materia publicitaria, que quedó circunscrita a las hipótesis de publicidad falsa y engañosa, sin incorporar normas sobre publicidad abusiva ni encubierta, como tampoco normas para proteger a ciertos destinatarios vulnerables, que sí las hay en el derecho comparado, como por ejemplo en la publicidad dirigida a niños.

- No hay modificación en materia de regulación por daños ocasionados por productos potencialmente peligrosos, particularmente en cuanto a considerar la "responsabilidad objetiva" del proveedor en los accidentes que pueden afectar la vida o integridad física de los consumidores (responsabilidad a todo evento).

- No se avanzó en uno de los mecanismos necesarios para la resolución de conflictos en materia de consumo: el arbitraje. Esto originalmente se consultó en el proyecto de modificación de la ley, pero en definitiva no prosperó.

- Finalmente, es inevitable hacer mención a lo que a la modificación gravemente le sobró. Esto es, el nuevo artículo 58, letra c), de la LPC, que contiene una advertencia impropia para el Servicio Nacional del Consumidor, a fin de que respete la libre competencia. Por el contrario, este servicio retrata el mercado y dados los nulos argumentos dogmáticos de esta modificación, no cabe más que concluir que es un celo excesivo o propio de los proveedores que tienen menores estándares de calidad reflejados en los estudios del Servicio Nacional del Consumidor. 